Fourth International Conference on Sustainable Construction Materials and Technologies http://www.claisse.info/Proceedings.htm

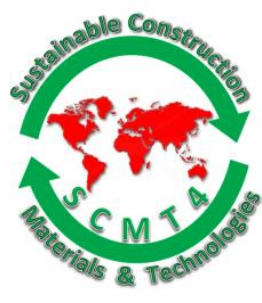

SCMT4

Las Vegas, USA, August 7-11, 2016

\title{
Development of Bridge Maintenance Management System in GIS Environment in India
}

\author{
Rajeev Goel $^{1 \mathrm{a}}$, Lakshmy Parmeswaran ${ }^{1 \mathrm{~b}}$, SK Sharma ${ }^{1 \mathrm{c}}$, Rajeev Garg ${ }^{1 \mathrm{~d}}$, GK Sahu ${ }^{1 \mathrm{e}}$ and JK \\ Goyal $^{1 \mathrm{f}}$
}

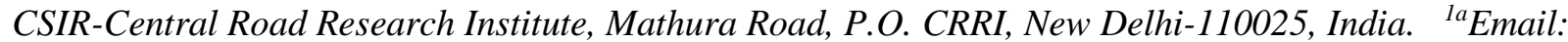

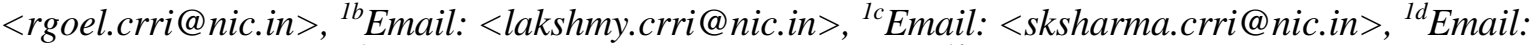
<rajeev.crri@nic.in>, ${ }^{1 e}$ Email: 〈gksahu1865@gmail.com>, ${ }^{l f}$ Email: <jkgoyal1966@gmail.com>.

\begin{abstract}
Bridges are lifelines of a Nation's road infrastructure and massive investments are being made in the highway sector every year in India. Since 1947, a large number of Reinforced Cement Concrete and Prestressed Cement Concrete bridges were built across the country and it is estimated that about $25 \%$ of them have distress in one form or the other. Presently, maintenance of bridges is in a rudimentary state and only a few important bridges are closely examined, that too on case-to-case basis for rehabilitation works. Considering that the numbers of bridges are increasing quite rapidly and their importance is also increasing, there is a need to develop a scientifically designed bridge management system in GIS environment for allocation of funds for maintenance, rehabilitation and strengthening of bridges on priority basis. Hence, a Bridge Maintenance Management System named as Indo-BMMS has been developed in GIS environment in the present study.
\end{abstract}

\section{INTRODUCTION}

As the allocated funds for the maintenance of the bridges are generally limited, so it is essential that the allocated funds for the bridge maintenance shall be used in such a way that they yield the highest possible benefit to society at the lowest possible cost. The actions to be carried out must be technically sound, object oriented and should take place at the right time. Considering the above, an initiative was taken to develop a GIS environment friendly Bridge Maintenance Management System (BMMS).

This paper gives brief details of developed software Indo-BMMS for the bridge maintenance management system in GIS environment. Using this developed software, allocation of the fund for maintenance, rehabilitation and strengthening can be prioritised in a scientific manner among the various bridges in a road network. The salient features of the software have also been discussed in detail.

\section{PRESENT KNOWLEDGE OF BRIDGE MAINTENANCE MANAGEMENT SYSTEMS}

\section{International Scenario}

Internationally, a need of BMMS was felt in seventies due to ever increasing number of grade separations on motorways / freeways / expressways. There have been several Bridge Management Systems available 
in various countries which have been developed by Government agencies as well as private agencies suitable for the bridges of their country and the funding pattern. Some available BMS softwares are BRUTUS (Norway); BRIMMS (Canada-DELCAN); BRIDGIT (USA/Canada-DELCAN); MATS (U.K.OXFORD COUNTY); WHOLF (U.K.-TRL); MMS (Denmark-COWI); and PONTIS (USA-Penn. DOT). Several countries have developed BMMS as per their traffic requirement.

Nowadays, BMMS in GIS environment are being used in many countries for managing highways and bridges. Such a system has been implemented and is being used to manage a $23000 \mathrm{Km}$ long roadway for a state government in Australia. This system was developed as a fully integrated web enabled application and contained both spatial and non-spatial components.

National Scenario. The bridge maintenance and management practices in India vary from Department to Department or State to State. No Indian State has a comprehensive management system consisting of various components viz. Inventory of bridges, Inspection and assessment of condition of bridges, Scientific analysis and bridge maintenance/repair needs, Assessment of requirement of funds at National/ State/ Project level, Maintenance scheduling, Identifying and prioritization of rehabilitation, Regular performance monitoring, Maintaining and constantly updating the Data Base, etc.

Ministry of Road Transport and Highways has prepared a Maintenance Inspection Manual (IRC:SP:351990) in the form of IRC guidelines. But different interpretations of these provisions may lead to a wide range of rating assessment for similar conditions. Therefore, there is a need for a comprehensive framework that covers all bridge conditions, yet is flexible enough for the evaluation agency to consider its own needs and willingness to invest resources, when necessary, in the evaluation investigations.

Like many other developing nations, in India too, there is a need for introducing bridge management programs, which provide for a long range bridge evaluation process that covers bridge condition, site traffic, maintenance and inspection cost.

\section{SOFTWARE INDO-BMMS}

Indo-BMMS is an interactive software and has been developed using VISUAL Studio 2008 for Front end, MS-SQL Server 2008 for Data base management and CRYSTAL Report for report generation. For the development of bridge/culvert inventory in GIS environment, commercially available software (ARCGIS, ARC-IMS and ERDAS) have been used.

Flow chart of the work of development of BMMS in GIS Environment for Maintenance of Bridges is given in figure 1. In developing this system, a comprehensive methodology has been adopted on the basis of the actual condition of the different components of a bridge and possible cost effective solutions for maintenance/ rehabilitation/ strengthening for allocation of budget on priority basis. The methodology and software Indo-BMMS is validated with respect to the data of the bridges on National Highways and State Highways, passing through district Ghaziabad in U.P., India.

Inventory Module. This is one of the main module in which all the data related to inventory of all the bridges and culverts on a network will be collected and stored in GIS environment. This module ties up the above information i.e. spatial and attribute such as name, age, structure type, location, purpose, traffic volume, details of construction and maintenance agency, topographical information, hydraulic data, geotechnical data, geometrical data, environmental data, structural design data, construction data, maintenance data, photographs, drawings, etc. This module has been validated by doing field studies on bridges of District Ghaziabad, as stated earlier. 


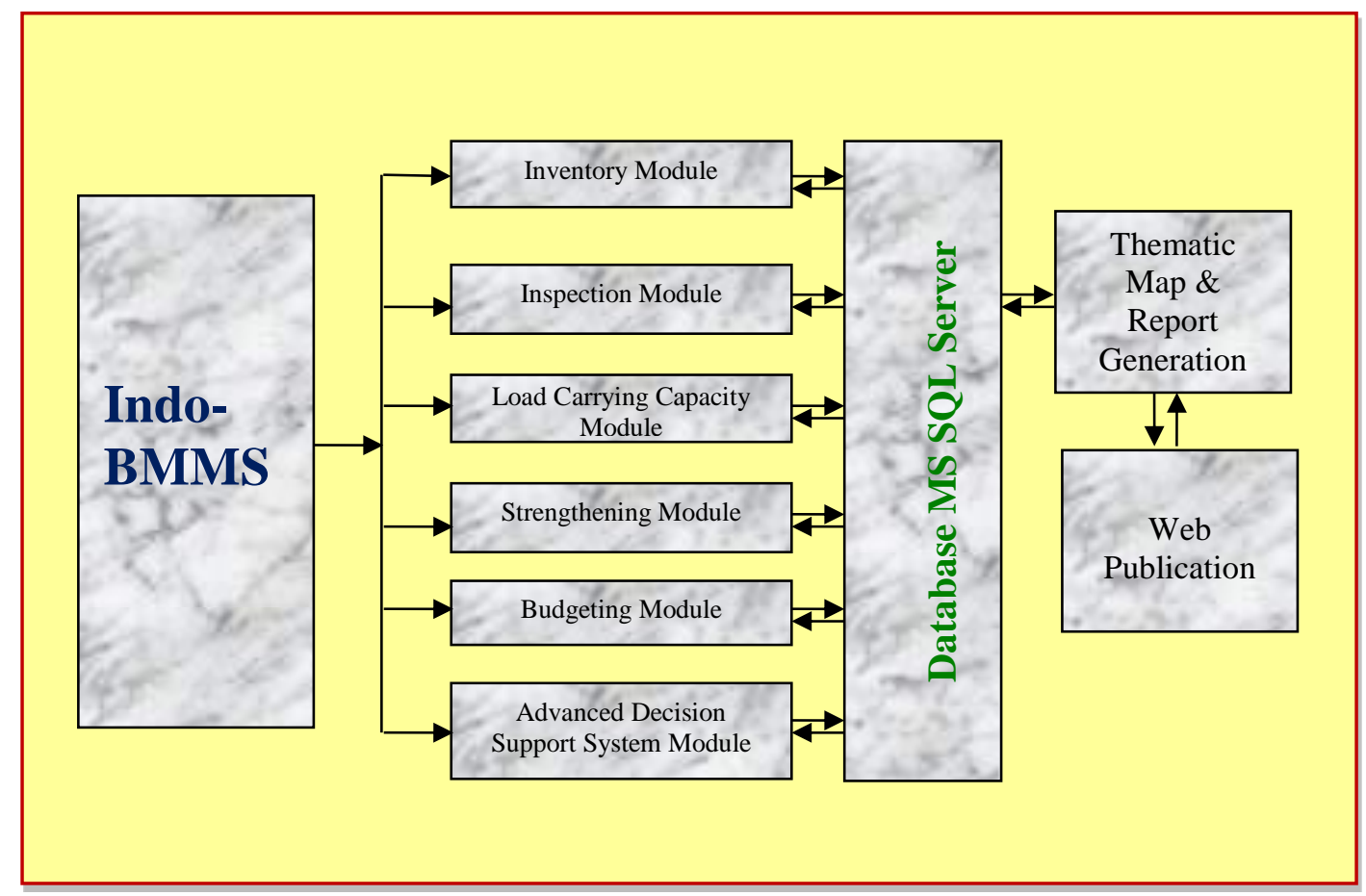

\section{Figure 1. Flow Chart of Bridge Maintenance Management System in GIS Environment}

To develop this module, the following methodology has been adopted in a network:

- Preparation of a base map of a network using survey of India Toposheets and Satellite data.

- Road inventory for National Highways and State Highways including Rail network and Water bodies.

- Collection of bridge and culvert related data including Chainage, Latitude and Longitude either from bridge owners or field survey

- Preparation of bridge and culvert inventory.

Different data layers were prepared from the mosaiced Satellite imageries of IRS LISS IV sensor. The description of these layers is given below:

- Road Layer

- Railway Layer

- Settlement Layer

- Ponds Layer

- Canal Layer

- River Layer

- Road bridge Layer

- Railway bridge Layer

- Culvert Layer

Flow chart, showing the various activities in preparation of GIS map is shown in figure 2. Several forms have been developed for feeding the gathered information under this module. The user can zoom down on the screen from a map to get the information of a specific bridge. This facility provides an easy and logical access to the bridge information. This module facilitates predefined output forms corresponding to routine enquiries. There can be several queries from the database. Some of these are given below as a sample: 
- To find out the number/location of major bridges on particular Highway/Network

- To find out the number/location of minor bridges on particular Highway/Network

- To find out the number/location of culverts on particular Highway/Network

- To find out the number of bridges in a particular block

As the data base of existing bridges and culverts, falling on National and State Highways, in district Ghaziabad has been created, so any query related to these can be answered in no time.

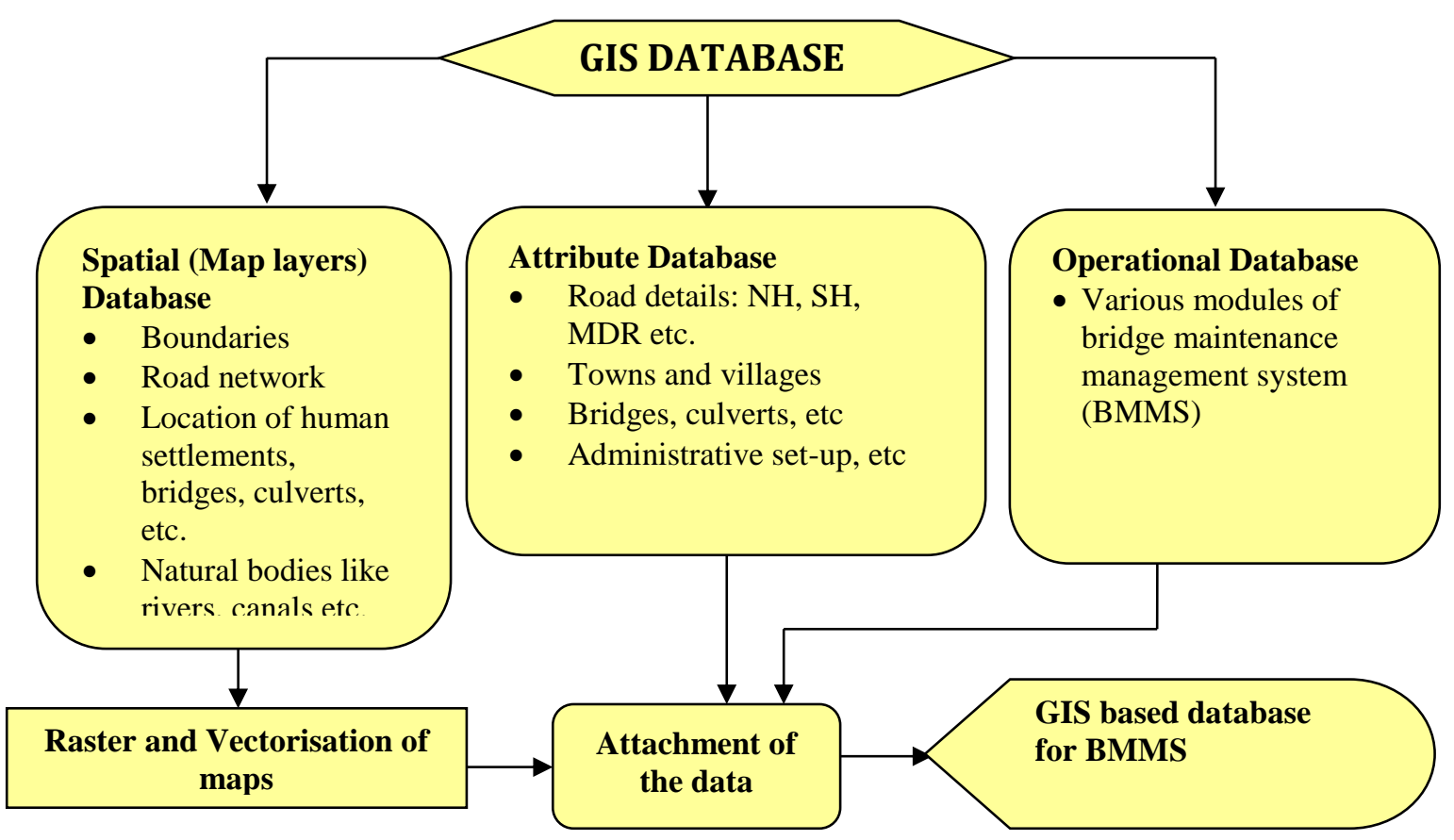

Figure 2. Activities Involved in Preparation of GIS map

\section{Inspection Module}

A strong data base is essential in order to make a scientific assessment of the present and future condition of the bridge. A reliable and complete documentation on the design and construction of the bridge is required. Field investigations need to be oriented primarily towards identifying the effect of any deterioration, damage or settlement that has taken place. Where such documentation is not available, then in addition to the above field investigations, dimensions of all the structural members need to be taken to prepare a complete set of as-executed drawings.

During inspection, all the structural as well as non-structural components of superstructure and substructure are thoroughly inspected. Defects, if any, noticed during inspection are also recorded. Following information is generally gathered during inspection of bridges:

- Cracking, spalling, honeycombing leaching, loss of material or delamination of concrete members in superstructure, substructure and foundations

- Corrosion of steel reinforcement, exposure of steel reinforcement, corrosion in prestressing tendons and structural steel members

- Measurement of crack width, scaling, shape and size of potholes

- Settlement, deformation or rotation, producing redistribution of stresses or instability of the structure 
- Hydraulic data covering scour, HFL, afflux, erosion at abutments etc.

- Effectiveness and condition of structural joints for steel bridges

- Condition of expansion joints, bearings and articulations hinges

- Any possible movement of abutments, piers, skew backs, retaining walls, anchorages

- Any settlement of foundations

After inspection of the bridges and culverts, gathered data is analysed to assess the severity of the distress and probable cause of the distress. To confirm the cause of the distress, some non-destructive as well as destructive tests need to be performed. These tests may include the following:

- $\quad$ Schmidt Rebound Hammer test

- Ultrasonic pulse velocity test for quality of concrete, crack depth and delamination

- Carbonation test

- Cover test

- $\quad$ Rapid Chloride Penetration test

- Half-cell Potentiometer Test

- Galva-pulse test

This module includes all the gathered inspection and testing data is feed through various forms and stored in the data base. This module also includes the data related to various inspection reports, maintenance work taken up from inception, testing results, if any, load carrying capacity carried out by the bridge authorities etc. Based on the data provided, software recommends further action to be taken by the bridge owner.

\section{Load Carrying Capacity Module}

Several of external agents from environment react with the concrete, steel, prestressing steel etc. and may degrade them, if the effects reach beyond certain threshold value. This degradation of material may influence the load carrying capacity of the bridge or its components apart from causing geometrical defects such as cracks, spalling etc. Following methodology is adopted in developing the software for this module:

- Analyse the existing bridge for self-weight and IRC loading and compute the bending moment to be resisted

- Compute the moment of resistance at the time of construction based on the design parameters

- Compute the moment of resistance (Capacity) based on the present condition of the bridge considering degradation of materials

- Compute the present rating of the existing bridge

- Compute the estimated time for initiation of following stages of corrosion:

- Corrosion initiation,

- Crack initiation,

- Delamination initiation,

- Spalling initiation

- Predict future rating and load carrying capacity of the bridge by assessing the rate of corrosion and estimating the reduction in areas of steel reinforcement due to effect of corrosion

Using the Inventory and Inspection data, this module is capable of analysing RCC slab and RCC T-girder bridges for IRC loadings. The present and future load carrying capacity of the bridges can be assessed, considering inbuilt appropriate degradation models for corrosion of steel in concrete due to chlorides and carbonation; and effects of alkali-silica-reaction.

From this module, the rating of bridge and its components can also be done. This module identifies the load deficient members and enables the owner to carryout appropriate rehabilitation or repair in a planned way. 


\section{Strengthening Module}

If the load carrying capacity of the existing bridges is less than the required one, then this module suggest various possible alternative strengthening measures for different component of the concrete bridges. In this module, all the possible defects in the various structural members (i.e. Deck slab, Longitudinal/transverse beams, Pier Cap, Pier etc.) of the concrete bridge such as Edge deterioration, Ponding of water, Leakage from construction joints, Scaling, Leaching, Dampness, Honeycombing, Cracking, Delamination, Spalling and Corroded / exposed reinforcement have been identified and classified in the different range of deterioration. Based on the different types of deterioration, this module will suggest the strengthening measures. Repair/strengthening measures for non-structural members such as railings, bearings etc. have also been suggested in this module.

\section{Advanced Decision Support System Module}

Prioritisation of maintenance must be based on carefully selected criteria and trade-off between them. Main objectives, generally expressed are to minimise the total risk for all bridges, maximise the performance of a system of bridges, minimise the maintenance cost or to maximise the usage of allocated budgets and to maximise the economic and social benefits from the maintenance. The most common policies that help to decide objectives or criteria fall into three categories: safety, cost and socio-economic benefits. Generally, social benefits are difficult to measure and quantify but GIS may be the right technology to help in these cases. The importance of each element for the function and safety of the bridge and the importance of the route is to be included in a model that calculates the ranking point for the bridge.

The methodology adopted for prioritization of bridge maintenance of a road network has been developed on the basis of Cumulative Index for Bridge Maintenance (CIBM). To estimate CIBM, following factors have been considered - Bridge condition index (BCI) based on the inspection data, Bridge Importance Index (BII), Hydraulic vulnerability rating (HCV) and Seismic vulnerability rating (SR). The Bridge Importance Index (BII) has been expressed as a function of its length, width, availability of alternate route, average annual daily traffic, socio-economic activities supported by road and rating on the basis of load restriction. The CIBM can be computed using Eq.1 which requires BCI, BII, SR and HV as inputs.

$$
\mathrm{CIBM}=-1.4+1.30 \mathrm{BCI}+0.75 \mathrm{HV}+0.45 \mathrm{SR}-0.4 \mathrm{BII}
$$

The Bridge Condition Index (BCI) explains the condition of a whole bridge based on the condition of each and every element of the bridge. Distresses are estimated considering their magnitude and severity in each of the bridge element. Thereafter, the product of both parameters is weighed considering the relevance of each element in respect of bridge structural integrity. The BCI is computed using Eq. 2.

$\mathrm{BCI}=\frac{\sum_{i=1}^{n} w_{i} m_{i} E C I_{i}}{\sum_{i=1}^{n} w_{i m_{i}}}$

where,

$\mathrm{w}_{i}$ is the weightage of the primary or secondary element $i$

$\mathrm{ECI}_{i}$ is the element condition index

$\mathrm{m}_{\mathrm{i}}$ is the material element factor

The bridge importance index (BII) reflects the importance of the bridge in the road network. It permits to represent the effects of presence of bridge in the road network for road users and in the national development. It depends on alternate route (AR) index, average annual daily traffic index (TI), Socioeconomic environment index (SEI), width (WI) length index (LI) and load restriction index (LRI) obtained from bridge inventory/ inspection module. 
where,

ARI is the Alternate route index

TI is the Average annual daily traffic index

SEI is the Socio-economic environment index

WI is the Width index for the bridge

LI is the Length index for the bridge

LRI is the Load restriction Index

The seismic risk (SR) is defined as the expectancy of failure probability /damage of the bridge due to the demand and its capacity. The seismic hazard is dependent on the geographical location of a structure and the seismic demand and capacity can be computed using the ground acceleration.

Hydraulic Vulnerability (HV) risk is defined as the probability that a part of the bridge (pier or foundation) or the whole structure fails or presents serious damage to hydraulic forces, given its configuration, environment characteristics and level of maintenance of its elements. It is mainly dependent on the river morphology and flow, bed /bank material, available clearances and characteristics of the component. Scour and bank erosion could weaken the foundations, piers and abutments. Based on the annual rain fall and flood hazard map of India, the hydraulic vulnerability rating is selected.

The visual inspection allows assessing the condition of river bed and banks, flow condition and scour level. Flow conditions are rated according to the probability of damage to the structure, considering that the flood may cover the deck. Scour is classified as the vulnerability of the piers or abutments that suffer local or generalized scour. Once the rating of hydraulic state is done using the flow conditions and scour, the lowest hydraulic rating of pier/abutment has to be selected.

The CIBM shall have a value between 1 and 10, Index 1 indicating Very Severe distressed condition and index around 10 indicates No distress condition of the bridge.

\section{Budgeting Module}

The objective of this module is to assess the requirement of funds for maintenance of bridges. On the basis of the various suggested strengthening measures for different components of the bridge, a cost effective solution to be selected on the basis of the availability of funds. The estimation and quantification of the repair and rehabilitation measures in terms of a BOQ gives an idea of funds requirement. This module takes the input from the all the previous modules.

Following steps have been followed in developing this module:

- Quantities of repair areas are obtained from Inspection module

- Identification of items for the rehabilitation measures is obtained from the Strengthening module with a reference to the nature of repair and retrofitting required

- Preparation of database of Scheduled items using MOST Data Book, Schedule of rates, Market rate analysis and available $\mathrm{BOQ} / \mathrm{Schedule}$ of rates of some of the ongoing/completed bridge rehabilitation works.

- Preparation of data base of Non-Schedule items which are not available in MOST data book, based on rate analysis and market survey.

- Estimation and costing of repair/strengthening measures component-wise

- Compilation of Bill of Quantities

As the cost estimate has been prepared using the rates of various items given in data book and schedule of 
rates, prepared by Ministry of Surface Transport, Govt. of India, so an appropriate escalation factor has to be used to arrive at the present cost.

\section{CONCLUSION}

Bridge maintenance management system consists of various components viz. Inventory of bridges, Inspection and assessment of condition of bridges, bridge maintenance/repair schemes, Assessment of requirement of funds for each bridge and prioritization of rehabilitation/maintenance of bridges on the basis of safety, cost and socio-economic benefits. The developed bridge maintenance management system Indo-BMMS provides information on possible scheme of maintenance and helps to allocate the budget to a particular bridge in a road network for its maintenance in a scientific manner. Recently, Ministry of Road Transport and Highways, Government of India has initiated the work of Inventory of bridges on National Highways.

\section{ACKNOWLEDGEMENTS}

Authors sincerely thank Department of Science and Technology, New Delhi for providing financial support to carry out this work. Authors also thank Director, CSIR-Central Road Research Institute, New Delhi for his encouragement and permission to publish this paper. Special thanks are due to all other project team members and others who directly or indirectly helped in carry out this work.

\section{REFERENCES}

IRC:6-2010. "Standard Specifications and Code of Practice for Road Bridges, Section II - Loads and Stresses (Sixth Revision)." Indian Roads Congress, New Delhi.

IRC:18-2000. "Design Criteria for Prestressed Concrete Road Bridges (Post-Tensioned Concrete) (Third Revision).” Indian Roads Congress, New Delhi.

IRC:21-2000. "Standard Specifications and Code of Practice for Road Bridges, Section III - Cement Concrete (Plain and Reinforced) (Third Revision)." Indian Roads Congress, New Delhi.

IRC:78-2000. "Standard Specifications and Code of Practice for Road Bridges, Section VII - Foundations and Substructure (Second Revision).” Indian Roads Congress, New Delhi.

IRC:83-1999 (Part I) . "Standard Specifications and Code of Practice for Road Bridges, Section IX Bearings, Part I : Metallic Bearings (First Revision).” Indian Roads Congress, New Delhi.

IRC:83-1987 (Part II) . "Standard Specifications and Code of Practice for Road Bridges, Section IX Bearings, Part II: Elastomeric Bearings.” Indian Roads Congress, New Delhi.

IRC:83-2002 (Part III) . "Standard Specifications and Code of Practice for Road Bridges, Section IX Bearings, Part III: POT, POT-CUMPTFE, PIN and Metallic Guide Bearings.” Indian Roads Congress, New Delhi.

IRC:SP:35-1990. “Guidelines for Inspection and Maintenance of Bridges

IRC:SP:37-2010. "Guidelines for Evaluation of Load Carrying Capacity of Bridges (First Revision)." Indian Roads Congress, New Delhi. 
IRC:SP:40-1993. "Guidelines on Techniques for Strengthening and Rehabilitation of Bridges." Indian Roads Congress, New Delhi.

Rajeev Goel, GK Sahu, BK Durai, Ram Kumar, P Lakshmy, Rajeev Garg, JK Goyal, VVLK Rao, AM Rao and SK Sharma (2013). "Development of Critical Infrastructure Information System in GIS Environment for Maintenance of Bridges on National \& State Highways (For validation, focus is kept on District Ghaziabad, UP)." CRRI Research Report No. CRRI/BAS/GAP-4456/2012-13/01, March 2013.

Rajeev Goel, Rajeev Garg, P. Lakshmy and Ram Kumar (2010). "Assessment of residual life of existing RCC bridges." Proceedings of the Joint IABSE-fib Conference on CODES IN STRUCTURAL ENGINEERING Developments and Needs for International Practice, Cavtat, Dubrovnik-Neretva County, Croatia, May 3-5, 2010, 1209-1216.

Rajeev Goel, Rajeev Garg and Ram Kumar (2009). "Assessment of present and future rating of existing RCC bridges." Proceedings of the First International Conference on Advances in Concrete, Structural and Geotechnical Engineering, Pilani, India, October 25-27, 2009, 1-10. 